\title{
MAPAS DIGITAIS INTERATIVOS COMO FERRAMENTA DE AUXÍLIO NA GESTÃO DE PROJETOS EM DESIGN: UMA ANÁLISE DA PLATAFORMA MY MAP.S
}

Interactive digital maps as a project management tool in design: an analysis of the my maps platform

Karina Pereira Weber', Larissa Fontoura Berlato', Berenice Santos Gonçalves', Luiz Fernando Gonçalves de Figueiredo'

RESUMO: Inserido na temática de mapas digitais interativos, como interface de visualização da informação, este artigo tem como objetivo avaliar a plataforma My Maps da Google. A análise se deu a partir dos princípios de design da informação por meio das variáveis visuais de Mijksenaar (1997) e métodos de mapeamento (LOCH, 2006; ARCHELA; THÉRY, 2008), avaliando suas funcionalidades e condições para uso como ferramenta estratégica de gestão de projetos. Como resultados, pontua-se que a plataforma é um recurso que potencializa a visualização de cenários, atores de sistemas, bem como valorização territorial por meio de narrativas que podem ser contadas nas descrições dos projetos mapeados, ainda que seja um tanto limitada para explorar os diferentes tipos de métodos de mapeamento. Os mapas digitais interativos, pelo My Maps, podem contribuir no processo de gestão de design em nível estratégico, auxiliando na visualização da informação.

PALAVRAS-CHAVE: Design da informação; Métodos de mapeamento; Mapas digitais interativos; Gestão estratégica de design.

ABSTRACT: Within the theme of interactive digital maps, as an information visualization interface, this article aims to evaluate the Google My Maps platform. The analysis was based on the principles of information design through the visual variables of Mijksenaar (1997) and mapping methods (LOCH, 2006; ARCHELA; THÉRY, 2008), evaluating its functionalities and conditions for use as a strategic management tool of projects. As results, it is pointed out that the platform is a resource that enhances the visualization of scenarios, system actors, as well as territorial valorization through narratives that can be told in the descriptions of the mapped projects, although it is somewhat limited to explore the different types of mapping methods. The interactive digital maps, through My Maps, can contribute to the design management process at a strategic level, helping to visualize the information

KEYWORDS: Information design; Mapping methods; Interactive digital maps; Strategic design management. 


\section{INTRODUÇÃO}

O design tem contribuído no âmbito da visualização da informação. Os mapas ajudam a representar espaços, cidades, caminhos e outras informações de modo a estruturá-las e facilitar sua compreensão. Eles servem como interfaces para representar um sistema de informação e contribuem para a construção de sentido e narrativas dos espaços, pois permitem uma compreensão mais ampla e contextual dos dados, podendo gerar novas associações antes não percebidas. Na atualidade, as mídias digitais potencializam a condição dessa visualização (MANOVICH, 2005), possibilitando representações e explorações espaciais de diversas maneiras, graças às novas tecnologias. O design, apropriando-se das ferramentas digitais, viabiliza ainda mais o entendimento espacial, pois consegue organizar e estruturar informações complexas (CARDOSO, 2011) e de diferentes categorias.

Como evolução dos mapas tradicionais, os mapas digitais interativos (ou MDI) têm sido utilizados como nova forma de explorar dados espaciais, permitindo uma compreensão mais complexa da visualização cartográfica. Eles representam potentes "ferramentas digitais para criação de imagens que representam a experiência espacial” (OLIVEIRA, 2014, p. 153). O mapa digital por si só não representa experiências, mas, a partir da sua elaboração, no processo de "ver" e "recriar" espaços, permite uma nova leitura, contribuindo para representação de experiências espaciais. Por facilitar a visualização de dados, os MDI podem ser utilizados como técnica para elaboração de estratégias que podem ser tomadas para fins diversos.

A criação de mapas temáticos ${ }^{1}$ tem sido um recurso pertinente para a pré-seleção de conteúdo em um contexto em que cada vez é maior o número de informações na rede. Assim, o MDI, para visualização cartográfica, contribui para concentrar informações relevantes sobre um determinado conteúdo e cenário (REIS, 2017).

De acordo com Manzini (2017), um cenário é um artefato comunicativo pelo qual se pode estabelecer diálogo para promoção de inovações sociais, pois permite pensar sobre o que fazer a partir de uma determinada situação ou diversas situações. Frente a isso, o uso de MDIs pode potencializar o desenho de cenários espaciais sendo um meio de visualização de cenários atuais e futuros (tal qual explicitado pelos artigos revisados e comentados no tópico 3.1), servindo de dados para gestão de projetos. Contribuem, portanto, para projetar experiências e conexões.

A partir do exposto, ressalta-se o contexto do problema desta pesquisa: os mapas já são utilizados em processos de desenvolvimento de projetos em design, por facilitar a compreensão contextual espacial. Esse processo tem sido facilitado pelas tecnologias que surgem para uso de pessoas que não dispõem, necessariamente, de conhecimento de sistemas e engenharias de informação, como a plataforma My Maps, disponibilizada pela Google. Contudo, demarca-se a necessidade de aprofundamento das qualidades, características e limitações das plataformas digitais e de explorar princípios do design da informação aplicados a este contexto (RICKER; JOHNSON; SIEBER, 2013). Portanto, a presente pesquisa buscou responder a seguinte pergunta: Como os princípios do design da informação e os de mapeamento podem ser aplicados na plataforma digital My Maps enquanto estratégias informacionais a auxiliar a gestão de projetos por meio de MDI?

O objetivo do presente artigo foi realizar a análise do My Maps quanto aos princípios do design da informação e quanto a relação que dispõe com os métodos de mapeamento, avaliando as funcionalidades e contribuições possíveis no processo de gestão estratégica de design, sendo estes os principais eixos teóricos abordados. Para tanto, adotou-se uma abordagem exploratória e qualitativa. 
Os procedimentos metodológicos foram conduzidos a partir de revisão sistemática de literatura nas bases de dados Elsevier Scopus e Web of Science, de técnicas de análise e avaliação (MIJKSENAAR, 1997; ARCHELA; THÉRY, 2008), e interpretação (FREIRE, 2013).

\section{FUNDAMENTAÇÃO TEÓRICA}

\section{Visualização da informação: mapas digitais interativos}

O design da informação potencializa a capacidade de expressão das demais disciplinas visuais do design, tendo como principal objetivo organizar, estruturar, ordenar e apresentar dados de modo a transformá-los em informação com sentido (QUINTÃO; TRISKA, 2013). Sua essência é proporcionar uma comunicação efetiva e clara. Tal contribuição nesse processo torna-se ainda mais relevante no momento em que estamos vivendo: na sociedade da informação.

Pela condição de transformar dados em informações, o design da informação contribui para o desenvolvimento de competências em informação por facilitar a recepção e interpretação da mensagem informacional, dando ao indivíduo condições de ação mais eficientes para acessar, avaliar e utilizar o conteúdo informacional disponível (DICK et al., 2017).

O design da informação é compreendido por Frascara (2004 apud DICK et al., 2017) como "design de comunicação visual”, pois cabe a ele interpretar, organizar e apresentar visualmente as mensagens a partir de elementos visuais e textuais tendo como premissa boa legibilidade e leiturabilidade (compreensão da informação). A organização visual dos elementos da mensagem deve seguir princípios que garantam ao indivíduo acesso, avaliação e correto uso (apropriação) das informações para garantir aprendizado ou comunicação útil. A Figura 1 demonstra a relação do design da informação com a competência em informação:

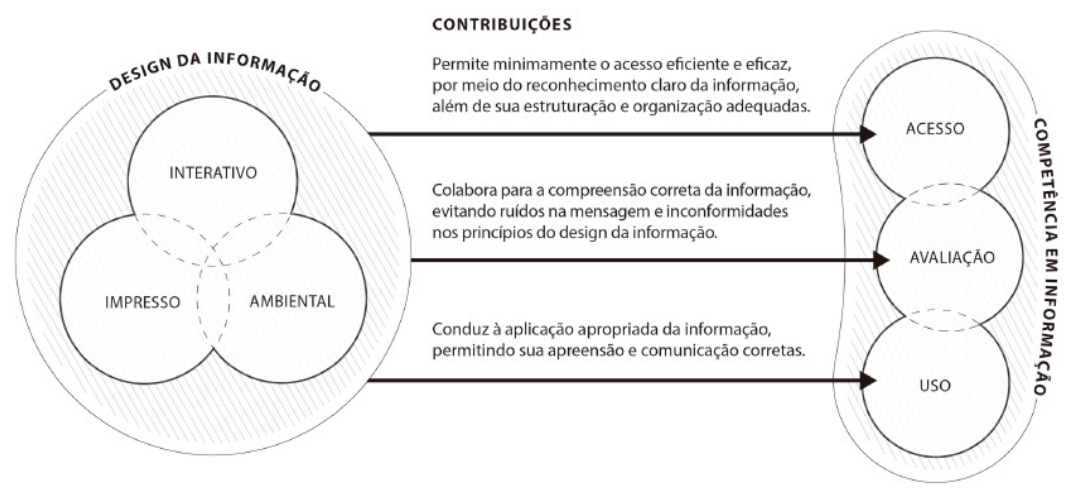

Ainda, a organização da informação deve ser planejada com base no contexto em que se dará a mensagem para evitar ruído tanto visual, quanto semântico. A performance da informação depende da capacidade do indivíduo em ver, compreender, memorizar e usar a informação (FRASCARA, 2015 apud DICK et al., 2017).

Mijksenaar (1997) considerou que o design tem a capacidade de dar forma à informação, a partir de recursos como: "enfatizar ou minimizar; comparar ou ordenar; agrupar ou classificar; selecionar ou omitir; optar pelo reconhecimento imediato ou tardio; e apresentá-la de forma divertida e interessante" (QUINTÃO, 2013, p. 42-43). Com base nos princípios desenvolvidos por Jaques Bertin em 1973 para cartografia, Mijksenaar (1997)
Figura 1: Relações entre design da informação e competência em informação Fonte: DICK et al., 2017, p. 10. 
Figura 2: Tradução livre Fonte: Mijksenaar (1997) adequou-os para o design, para serem não só utilizadas em cartografia, mas para contribuírem em projetos de sinalização e design da informação, potencializando a organização e avaliação de informações. Mijksenaar (1997) classificou-as em três: diferenciação, hierarquia e apoio (Figura 2):

\begin{tabular}{ll}
$\begin{array}{ll}\text { Diferenciação } \\
\text { classifica de acordo com a categoria e o } \\
\text { tipo }\end{array}$ & $\begin{array}{l}\text { Cor } \\
\text { llustração } \\
\text { Largura da coluna } \\
\text { Fonte tipográfica }\end{array}$ \\
& $\begin{array}{l}\text { Posição sequencial (cronologia) } \\
\text { Posição na página (leiaute) } \\
\text { Tamanho das fontes } \\
\text { Peso das fontes } \\
\text { classifica de acordo com a importância } \\
\text { Espaçamento de linhas }\end{array}$ \\
$\begin{array}{l}\text { Apoio } \\
\text { acentua e enfatiza }\end{array}$ & $\begin{array}{l}\text { Áreas de cores e sombras } \\
\text { Linhas e blocos } \\
\text { Símbolos, logos, ilustrações } \\
\text { Atributos do texto (itálico, etc.) }\end{array}$ \\
\hline
\end{tabular}

Entende-se que a função do design da informação na criação de MDIs está em organizar os dados e complexidades cognitivas a fim de facilitar o uso e entendimento das informações. Desse modo, percebe-se a possibilidade de explorar a aplicação dos princípios de design da informação propostos por Mijksenaar ao contexto da cartografia na criação de MDIs, pois contribuem para o planejamento e organização das informações.

\section{MÉTODOS DE MAPEAMENTO}

Os mapas tradicionais, não digitais, possuem uma sistematização própria e seguem alguns métodos de mapeamento que permitem a análise e compreensão da informação exposta (LOCH, 2006). O conhecimento desses métodos ajuda no processo de projetação de mapas temáticos e auxiliam para a organização, estruturação e hierarquização das informações. Segundo Archela e Théry (2008), os mapas temáticos podem representar: [i] fenômenos qualitativos - em que se utilizam as variáveis visuais (cor, forma, linha) para indicar regionalização do espaço pela presença ou ausência de marcações, rotas, deslocamento no espaço, indicam diferenças nominais com uso de cores sem que haja necessariamente ordem ou hierarquia; [ii] fenômenos ordenados - representam a ordem dos fenômenos em variação de valor (uso de transparência) para representar as zonas; [iii] fenômenos quantitativos - utilizam a variável visual de tamanho para indicar quantidades, usam símbolos proporcionais que ajudam no entendimento da informação, como linhas de espessuras variadas, pontos em escalas diferentes.

\section{Mapas digitais interativos: interfaces de informação geográfica}

As interfaces digitais configuram-se cada vez mais para proporcionar autonomia no processo interativo com os usuários. A interface é um canal cujo objetivo é dispor uma linguagem, comunicação e informação com um indivíduo por meio da qual, segundo Freitas (2005), constrói-se um código apropriado que compõe a cultura imaterial. O principal desafio de uma interface é possibilitar o uso com uma linguagem decodificável. Se o MDI é considerado como uma interface, significa que ele deve ser capaz de informar adequadamente os dados geográficos e espaciais a partir de uma interação que facilite a compreensão da informação.

Falat (2007) trouxe a concepção de interface relacionada a MDI como aquela que "pode ser considerada tanto um meio para a interação usuário-sistema, quanto uma ferramenta que oferece os instrumentos para permitir e facilitar este processo comunicativo” (FALAT, 2007, p. 13). 
A interatividade em mapas digitais se dá no modo como a visualização cartográfica muda conforme se apresenta ao usuário e o mesmo interage com os dados. O usuário pode, então, interagir com os dados e estes modificarem-se em resposta à ação do usuário (FALAT, 2007).

Segundo a autora, quando se pensa em interface interativa para cartografia, deve-se explorar técnicas que contribuam para a visualização da informação de maneira adequada. Falat (2007) citou algumas funções básicas que devem possuir como: zoom in e zoom out, para alterar a escala, nível de generalização da informação, deslocamento (panning), acesso à informação dos atributos e manipulação de parâmetros de representação, como cor e textura (FALAT, 2007, p. 15).

Com base nas noções sobre design de interface e design de informação, a análise do My Maps objetiva entender como está organizada sua interface com relação a organização informacional contribuindo na geração de mapas digitais. A partir dessa análise, visa-se entender a "competência” dessa mídia como recurso a apoiar estratégias de gestão de design.

\section{Criação de estratégias de design a partir de mapas digitais interativos}

Como uma mídia que pode fornecer informações geográficas, o MDI contribui na gestão de informação e tomada de decisão (FALAT, 2007). Por meio dele é possível armazenar, manipular e fazer a gestão das informações geográficas (SOUSA, 2015). A contribuição do design para organização de informações geográficas está na interpretação dos dados e reconstrução, ou “rediagramação" (QUINTÃO, 2013), gerando informações que condizem com as capacidades cognitivas das pessoas para interpretarem mais facilmente.

Os mapas, além de sintetizar e organizar as informações, também ajudam na construção de sentido sobre os espaços. Eles podem oferecer detalhes sobre os territórios, valorizando-os por poder destacar informações específicas, construindo uma narrativa sobre os mesmos. Tal qual ocorre em mapas digitais, sendo estes potencializados pela possibilidade de ambientes digitais uma vez que: "o ambiente digital oferece informações que são topologicamente distribuídas em arquiteturas que podem, inclusive, simular ambientes físicos em que há a ilusão de circulação espacial” (BRESSANE, 2010). Assim, o ambiente digital possibilita a manipulação de informações que facilitam a "reconstrução" de ambientes físicos, organizando-as pela arquitetura de informação conforme se deseja visualizar as informações, construindo ritmo e sentido à mensagem.

Murray (2003) apontou quatro propriedades dos ambientes digitais que caracterizam-nos. Segundo a autora, eles podem ser: [i] procedimentais, respondendo com comportamentos pré-configurados, contribuindo no funcionamento e interação de uma interface com o usuário a partir da interpretação de mundo baseada em regras exatas ou gerais; [ii] participativo, criado a partir de um universo narrativo que antevê as possíveis interações dos usuários utilizando convenções literárias que permitam responder às interações; [iii] espaciais, a qualidade espacial é criada pelo processo interativo, nos meios digitais está relacionada aos movimentos e interações possíveis, bem como no nível de detalhamento de descrições sobre os espaços gerando uma conexão do usuário com o espaço digital independentemente da sua localização geográfica; [iv] enciclopédico, tem a ver com a expectativa de recuperação de informação gerada pela potencialidade de armazenamento dos computadores. A partir dos ambientes digitais é possível criar narrativas com potencial artístico ricas em informações, mesclando diversos tipos de mídia na construção de sentido. $O$ desafio atual é explorar essas potencialidades dos ambientes digitais. 


\section{PROCEDIMENTOS METODOLÓGICOS}

Esta pesquisa tem abordagem qualitativa, com objetivo exploratório e descritivo quanto às funcionalidades e potencialidades de uso que o My Maps oferece como ferramenta ao processo de gestão estratégica de projetos de design, a partir de revisão sistemática de literatura, da avaliação sobre a possibilidade de aplicação na plataforma dos princípios de design da informação e dos princípios da cartografia para a criação de mapas temáticos.

Desta forma os procedimentos metodológicos abaixo descritos serão para analisar e avaliar a plataforma como possível ferramenta a contribuir na gestão de projetos a partir do estudo dos recursos informacionais disponíveis, podendo ser implementada como recurso de gestão de design em nível estratégico (MOZOTA, 2011). Nesse sentido, estabelecem-se quatro etapas: [1] resgate investigativo do uso do My Maps em pesquisas acadêmicas; [2] levantamento de dados, organização e construção da lógica de apresentação para inserção no mapa; [3] análise dos princípios de design da informação com base nas variáveis visuais de Mijksenaar (Figura 2) e [4] avaliação sobre as possibilidades de seguir os métodos de mapeamento dentro da plataforma para criação de mapas temáticos para gestão de projetos.

\section{Resgate investigativo do uso do My Maps em pesquisas acadêmicas}

Por se tratar de uma plataforma de alcance mundial, foi realizada uma busca sistemática da literatura visando identificar e analisar artigos nacionais e internacionais que utilizem a plataforma My Maps na gestão de projetos, de modo a aprofundar o entendimento sobre suas possibilidades de uso com esta finalidade. Esta busca foi realizada no dia 17 de agosto de 2020, adotando o termo de busca "my maps".

Como critério de seleção das fontes, foi buscado nas maiores bases de dados na área de Ciências Sociais que incluem artigos em periódicos e conferências os quais possam ser acessados através do sistema CAPES. O resultado desta seleção foram as seguintes fontes de busca: Elsevier Scopus e Web of Science. Com relação ao acesso, foram analisados os artigos acessíveis por meio do Portal de Periódicos da CAPES na UFSC; Google Acadêmico; portal das editoras de forma gratuita e através do sistema COMUT nas instituições envolvidas. Não foram aplicados filtros com relação ao ano de publicação, à língua e à área de pesquisa visando ampliar a pesquisa. $\mathrm{O}$ resultado encontrado foi de 35 artigos conforme Tabela 1:

Tabela 1: Resultados da busca sistemática da literatura

Fonte: Os autores.

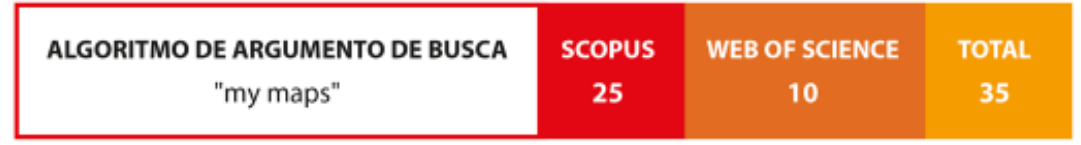

O primeiro processo de filtragem foi a identificação das publicações repetidas por meio do uso do gerenciador bibliográfico Mendeley. Nesta etapa foram excluídos por títulos as publicações repetidas, resultando em 28 artigos. 0 segundo processo de filtragem referiu-se à leitura dos títulos, resumo e palavras-chave dos artigos com o objetivo de verificar a adequação destes com o tema da pesquisa, permanecendo 6 artigos que demonstraram relevância com o tema, conforme a Figura 3: 


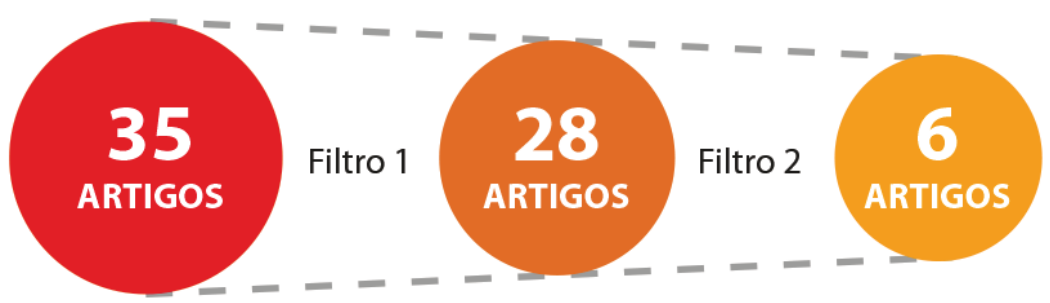

Figura 3: Processo de filtragens

Fonte: Os autores.

Posteriormente, foi realizado um terceiro filtro a partir da leitura integral dos artigos, permanecendo os 6 artigos previamente selecionados. Por fim, obteve-se o portfólio final de referências conforme apresentado na Tabela 2:

\begin{tabular}{|c|c|c|c|c|}
\hline & REFERÊNCIAS & ANO & PAÍS & ÁREA \\
\hline 1 & $\begin{array}{l}\text { ARUMUGAM, Sharan Kumar; MUHAMAD, Rahimah; YAHYA, } \\
\text { Khairulzan. Mapping of construction waste for eco-costs per } \\
\text { value ratio (EVR) index using Google My Maps in Shah Alam, } \\
\text { Malaysia. In: 4th International Conference on Construction } \\
\text { and Building Engineering \& 12th Regional Conference in } \\
\text { Civil Engineering (ICONBUILD \& RCCE 2019), v. 849, issue 1, } \\
\text { article number 012046, 2020. DOI: } 0.1088 / 1757- \\
899 X / 849 / 1 / 012046 \text {. }\end{array}$ & 2020 & MALÁSIA & $\begin{array}{l}\text { Engineering e } \\
\text { Materials Science }\end{array}$ \\
\hline 2 & $\begin{array}{l}\text { FALCO, Enzo; ZAMBRANO-VERRATTI, Jesús; KLEINHANS, } \\
\text { Reinout. Web-based participatory mapping in informal } \\
\text { settlements: The slums of Caracas, Venezuela. Habitat } \\
\text { International, v. } 94, \text { p. } 102038,2019 . \text { DOI: } \\
\text { https://doi.org/10.1016/j.habitatint.2019.102038. }\end{array}$ & 2019 & $\begin{array}{l}\text { ITÁLIA e } \\
\text { HOLANDA }\end{array}$ & Social Science \\
\hline
\end{tabular}

KUPSCH, Stephan; VENTAYEN, Randy Joy M.; CRUZ, Josephine S. Dela. Plotting a healthy apiary location using

3 WebGIS. In: Proceedings of the 8th International Conference on Informatics, Environment, Energy and 2019 FILIPINAS Computer Science Applications. 2019. p. 54-58. DOI: https://doi.org/10.1145/3323716.3323726.

\begin{tabular}{|c|c|c|c|c|}
\hline 4 & $\begin{array}{l}\text { SABARISH, B. A. et al. Recommendations of location for } \\
\text { facilities using domination set theory. In: } 2017 \\
\text { International Conference on Communication and Signal } \\
\text { Processing (ICCSP). IEEE, 2017. p. 1540-1544. DOI: } \\
\text { 10.1109/ICCSP.2017.8286646. }\end{array}$ & 2018 & ÍNDIA & Computer Science \\
\hline 5 & $\begin{array}{l}\text { BONG, K. et al. Deepwater Northwest Borneo Geohazards } \\
\text { Catalogue: Impact on Hydrocarbon Exploration and } \\
\text { Development. In: Offshore Technology Conference Asia. } \\
\text { Offshore Technology Conference, 2018. DOI: } \\
\text { https://doi.org/10.4043/28513-MS. }\end{array}$ & 2018 & EUA & $\begin{array}{l}\text { Energy e } \\
\text { Engineering }\end{array}$ \\
\hline 6 & $\begin{array}{l}\text { RICKER, Britta A.; JOHNSON, Peter A.; SIEBER, Renee E. } \\
\text { Tourism and environmental change in Barbados: gathering } \\
\text { citizen perspectives with volunteered geographic } \\
\text { information (VGI). Journal of Sustainable Tourism, v. 21, } \\
\text { n. 2, p. } 212-228,2013 \text {. DOI: } \\
\text { https://doi.org/10.1080/09669582.2012.699059. }\end{array}$ & 2013 & CANADÁ & $\begin{array}{l}\text { Business, } \\
\text { Management and } \\
\text { Accounting e } \\
\text { Social Sciences }\end{array}$ \\
\hline
\end{tabular}

Tabela 2: Portfólio final de referências

Fonte: Os autores. 
O estudo de Arumugam, Muhamad e Yahya (2020) se concentrou no mapeamento da geração de resíduos de construção em canteiros de obras residenciais usando o aplicativo My Maps. Foram coletadas informações como coordenadas, fotos, tipos de materiais, tipos e quantidade de resíduos, área de construção, custo de trabalho, vida útil do material e índice de eco-custo por valor (EVR) para monitoramento. Os dados coletados foram inseridos no My Maps via AppSheet para o processo de mapeamento. $\mathrm{O}$ sistema proposto por este estudo visa auxiliar no monitoramento do total de resíduos de construção gerados desde o início de uma obra. Nesse sentido, os autores reforçaram a importância do uso de banco de dados para o monitoramento de desperdício de materiais que comprometem o desenvolvimento sustentável pelo impacto de construções civis. Ainda, demonstraram a importância em adquirir os dados relevantes para este caso e utilizá-los para desenvolver e monitorar por meio dos bancos de dados.

A pesquisa de Falco, Zambrano-Verratti e Kleinhans (2019) explora o potencial das ferramentas de mapeamento participativo baseadas na web para fins de planejamento urbano e criação de informações espaciais em assentamentos informais, visando principalmente à identificação e mapeamento de instalações públicas e obras públicas planejadas e em construção. Entre os resultados obtidos com esse mapeamento, identificam-se a sua utilidade no planejamento de projetos públicos entre Setores e Comunas e no aumento da conscientização dos residentes locais dos conselhos comunais.

No estudo de Kupsch, Ventayen e Cruz (2019), o My Maps foi utilizado para traçar áreas para implantação de apiário que são favoráveis, neutras ou menos favoráveis de forma pública, gratuita, rápida, divertida e acessível para leigos em TI. De forma semelhante à pesquisa apresentada neste artigo, foi explorado o uso de cores para a rápida identificação de agrupamento de informações, salientando visualmente as áreas mais adequadas para a implementação de apiários. A escolha pela plataforma por estes pesquisadores também se deu por ser gratuita e não demandar conhecimentos aprofundados em linguagens de programação.

O artigo de Sabarish et al. (2018) visa a identificação dos conjuntos dominantes plausíveis do gráfico da cidade, o que ajudará os algoritmos de localização de instalações úteis, como escolas, hospitais e delegacias de polícia, a determinar os locais apropriados para as instalações benéficas corretas a partir do My Maps para formar um gráfico.

A pesquisa de Bong et al. (2018) tem como foco o gerenciamento de geohazards pelo Catálogo de Geohazards que utiliza o My Maps potencializando a eficácia e a eficiência do fluxo de trabalho de avaliação de riscos geográficos de águas profundas que impactam nas atividades de perfuração e desenvolvimento de campo da Shell.

A pesquisa de Ricker, Johnson e Sieber (2013) investiga o uso de ferramentas Geospatial Web 2.0 (Geoweb) para coletar informações geográficas voluntárias (VGI) sobre mudanças ambientais relacionadas ao turismo de cidadãos de Barbados. A abordagem se deu a partir de workshops de mapeamento participativo, utilizando My Maps, o qual permitiu aos usuários interagir com imagens detalhadas de satélite de Barbados. Os autores analisaram como os participantes usaram o My Maps, identificando questões de precisão, integridade dos dados e alfabetização digital/ informática. Entre os resultados obtidos, identifica-se outras necessidades de pesquisa como design de interface de usuário, precisão e incerteza, e como gerenciar vários níveis de alfabetização digital.

Os artigos selecionados apontam o uso do My Maps para diferentes temáticas projetuais e com diferentes objetivos no uso dos dados mapeados. Em nossa pesquisa, a construção do mapa se deu com o intuito de otimizar a percepção de oportunidade de conexões entre diferentes projetos desenvolvidos no NAS Design. Possibilidades de conexões podem contribuir para fortalecer diferentes comunidades parceiras do Núcleo e seus diferentes atores, de modo que conheçam umas às outras por projetos que contemplem realidades semelhantes, ainda por meio do serviço ou atividade 
de uma que sirva a outra, como fornecendo um produto local que possa apoiar a atividade de uma outra comunidade, entre outras possibilidades de conexões e apoio que otimize os trabalhos locais e os avanços dos projetos acadêmicos. A pesquisa relatada neste artigo enfatiza uma etapa anterior, no sentido de explorar a ferramenta para a construção de MDI, e o uso da plataforma enquanto ferramenta de gestão de projetos propriamente dita ainda está sendo incorporada aos poucos pelo núcleo. Pois, conforme Ricker; Johnson e Sieber (2013) mencionaram, existe a necessidade de produções de pesquisas explorando o design de interface para aprimorar mapas digitais. Tal discussão é contemplada aqui, buscando demonstrar como os princípios do design da informação são possíveis de serem explorados na plataforma analisada, e suas relações com a interação entre usuários e mapas, entendo os mapas digitais como interface de visualização da informação que pode seguir metodologias de cartografia para seu aprimoramento.

\section{My Maps}

A Figura 4, apresentada como infográfico, expõe as potencialidades básicas, disponíveis na versão online, sem uso de programação, presentes na plataforma My Maps para a criação de MDIs, por meio de suas ferramentas. Segundo a descrição feita pela Google, uma das possibilidades pensada para o uso da ferramenta é a documentação de atividades acadêmicas.

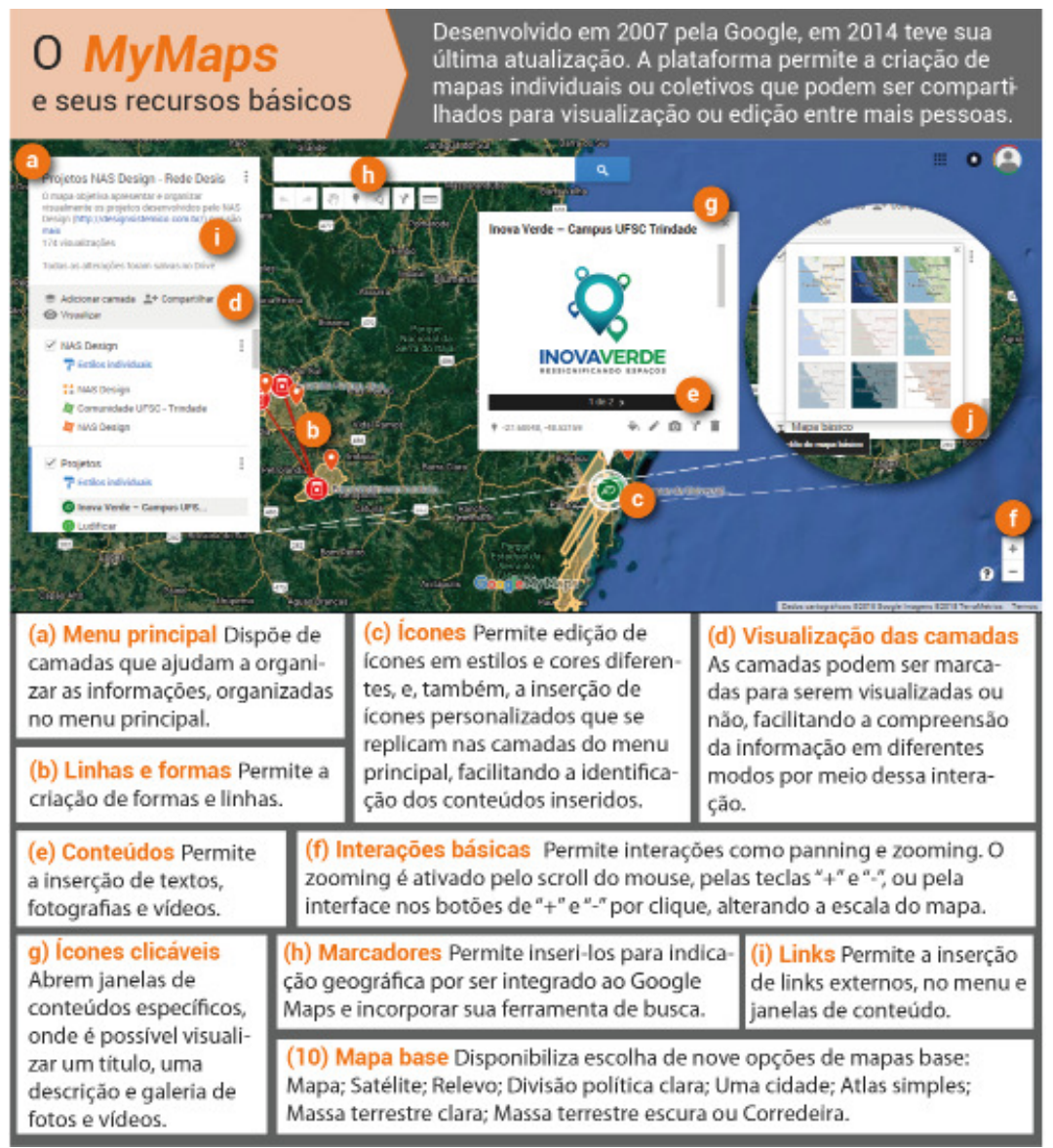

Figura 4: Infográfico apresentando as potencialidades do My Maps

Fonte: Os autores 
A escolha por essa plataforma se dá por ser de fácil acesso a partir de conta de e-mail da Google, a qual as gestoras dos projetos têm acesso; permite a integração com o Google Drive, também já utilizado pelas gestores para compartilhamento de documentos; além de utilizar como base o Google Maps, com o qual as gestoras possuem familiaridade.

As gestoras desse projeto são duas alunas de doutorado do Pós-Design da Universidade Federal de Santa Catarina (UFSC), pesquisadoras do Núcleo de Abordagem Sistêmica do Design (NAS Design) da UFSC e autoras deste artigo. O NAS Design desenvolve projetos na área de design relacionados à sustentabilidade em um processo holístico, com foco no sistema produtivo e suas complexas interações (MARTORANO, 2012; JOLY; STRAIOTO; FIGUEIREDO, 2014). O mapa criado para o NAS Design será atualizado com informações de projetos novos, em execução e já executados, criando uma rede visual conectiva entre diferentes comunidades e atores, destacando as características, atividades, serviços e outras informações pertinentes de cada comunidade, de modo que a cada novo projeto ou demanda local, seja possível repensar novas parcerias, novas cadeias entre estes nós. Mas, o mapa ao ser divulgado pelo NAS Design também contribui para apresentar os tipos de projetos realizados pelo núcleo bem como evidenciar as comunidades parceiras com quem os acadêmicos trabalham, de modo a contribuir para suas valorizações e reconhecimentos. A etapa de identificação e seleção dos projetos do NAS Design realizou-se de forma colaborativa, com a participação de todos os atores desse núcleo, incluindo alunos de graduação, mestrado e doutorado, bem como o professor Dr. Luiz Fernando Gonçalves de Figueiredo, responsável pelo núcleo e co-autor deste artigo. A etapa de desenvolvimento do MDI foi realizada pelas gestoras desse projeto.

A plataforma será analisada na sua versão desktop, pois foi verificado que essa versão possui mais opções de interação e diferenciação das informações em comparação a sua versão app.

Figura 5: Tela do My Maps para desktop com o mapa

Fonte: Criado pelos autores. $^{2}$

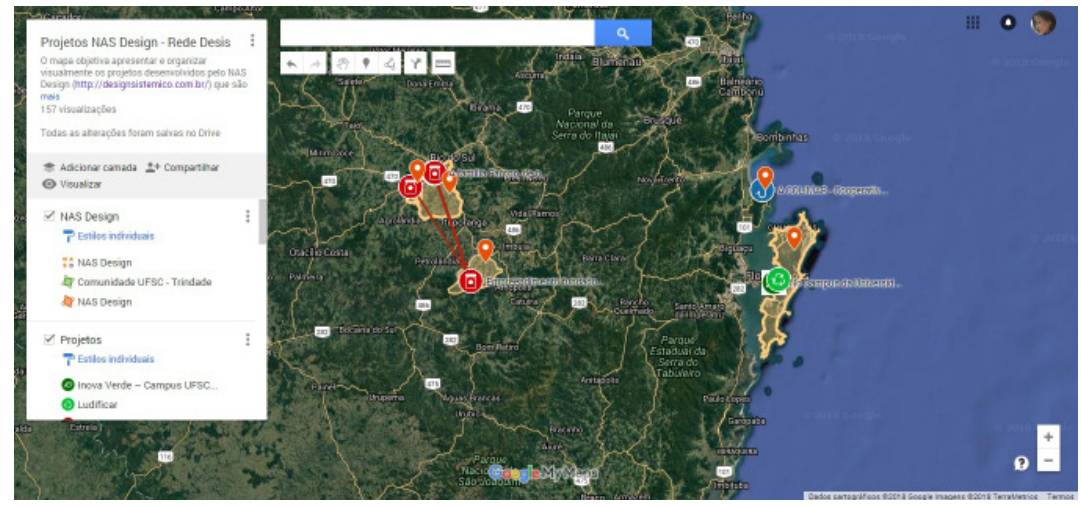

ETAPAS DE AVALIAÇÃO E ANÁLISE

\section{Documentação de projetos para criação do mapa temático no my maps}

A partir do entendimento da plataforma, a etapa inicial consistiu em organizar os dados dos projetos a serem inseridos na mesma. Organizou-se inicialmente por categorias de informação: título do projeto, descrição do projeto, links relacionados aos projetos, imagens, níveis de hierarquia das informações. Após, entendeu-se que a plataforma dispunha na versão gratuita (versão escolhida como início de implementação desse tipo de recurso na gestão de projetos) de apenas 10 camadas para inserção de conteúdo, onde optou-se por organizá-las da seguinte maneira: 
1) camada para apresentação e demarcação geográfica do núcleo de pesquisa e extensão; 2) camada constando todos os projetos do núcleo; 3) camada com a demarcação geoespacial das localidades em que os projetos são realizados; 4) camada para demarcação com ícone apontando as cidades em que se realizam os projetos; 5) camada para demonstrar as conexões temáticas, onde é possível visualizar facilmente os projetos que abordam os mesmos temas e podem ser relacionados; 6) camada para legenda explicando os ícones que foram inseridos. Por se tratarem de ícones personalizados, feitos pelos autores para manter a identidade utilizada pelo núcleo, considerou-se interessante uma camada para legenda (pois é o único modo de colocar legendas) contextualizando os ícones aos temas abordados nos projetos desenvolvidos pelo núcleo. A organização, estruturação e escolha de cores para implementação do mapa consideraram os métodos já consolidados para mapeamento, avaliando, com base na documentação dos projetos, o tipo que melhor se enquadraria ao que o núcleo deseja visualizar para, então, começar o desenho do mapa.

Para a criação do mapa temático optou-se, entre as nove possibilidades, pelo uso do mapa de base Satélite, por facilitar a compreensão do espaço mais próximo da realidade. Percebeu-se que esse tipo de apresentação do mapa não compromete o entendimento da informação sobre os projetos, como será explicado na análise.

\section{Análise com base em princípios do design da informação}

A análise da ferramenta será embasada nas variações visuais apresentadas na Figura 2, de Mijksenaar (1997). O objetivo é verificar se a ferramenta permite a criação de mapas que estejam de acordo com os princípios do design da informação apontados por Mijksenaar, e se contribuem para o entendimento das informações ajudando no processo de gestão de projetos.

\section{Avaliação da ferramenta quanto aos métodos de mapeamento}

Após a análise das variações visuais, será feita uma avaliação da plataforma quanto aos recursos disponíveis para criação de mapas seguindo os métodos de mapeamento apresentados anteriormente. $O$ intuito é avaliar a eficácia da mesma na aplicação desses conceitos que contribuem para uma boa visualização dos dados cartográficos, sendo critérios importantes para a consolidação de dados com intuito científico.

\section{ANÁLISE E AVALIAÇÃO}

A análise inicial aborda as variações visuais que são possíveis de aplicar na criação do mapa temático. A partir da proposta de Mijksenaar (1997), algumas variáveis foram elencadas como pertinentes para a construção do mapa temático em questão, e sobre estas variáveis é que será feita a análise. São elas: [i] quanto à diferenciação: Cor, ilustrações; [ii] quanto à hierarquia: posição sequencial cronológica, posição na página, tamanho das fontes, peso; espaçamento das linhas e [iii] quanto ao apoio: áreas de cores e sombras, linhas e blocos; atributos do texto, imagens/vídeos e links. O mapa também foi construído a partir da sistematização com base nos métodos de mapeamento para representação dos fenômenos qualitativos, conforme abordado no tópico 2.2. Para apresentar este tópico, foram criados infográficos (Figuras 7, 8, 10 e 12) para cada variação visual, apresentando as opções oferecidas na construção de mapas quanto às variações, bem como as escolhas que foram feitas na utilização dos elementos e recursos disponíveis na plataforma para a criação do mapa.

Com relação a diferenciação, o elemento que pode ser mais explorado, foi a variação de cor, com seus elementos (Figura 6): 


$\begin{array}{ll}\text { Diferenciação } & \text { Elementos em que as variações se dão: } \\ \text { Cores } & \begin{array}{l}\text { (a) marcadores, (b) formas, (c) linhas, (d) conteúdo das } \\ \text { camadas; (e) informação sobre a interação; (f) desenho de } \\ \text { linhas e formas; (g) links, (h) janelas de edição e conteúdo }\end{array} \\ & \text { (i) marcadores com icones; (j) ações que podem ser realizadas } \\ \text { nlustraçöes } & \text { no mapa; (k) açães que podem ser realizadas para organizar os } \\ & \text { dados no mapa; (l) icone de ajuda }\end{array}$

Figura 6: Lista de elementos com características de diferenciação que são possíveis de implementar e foram utilizadas na criação do mapa temático

Fonte: Os autores

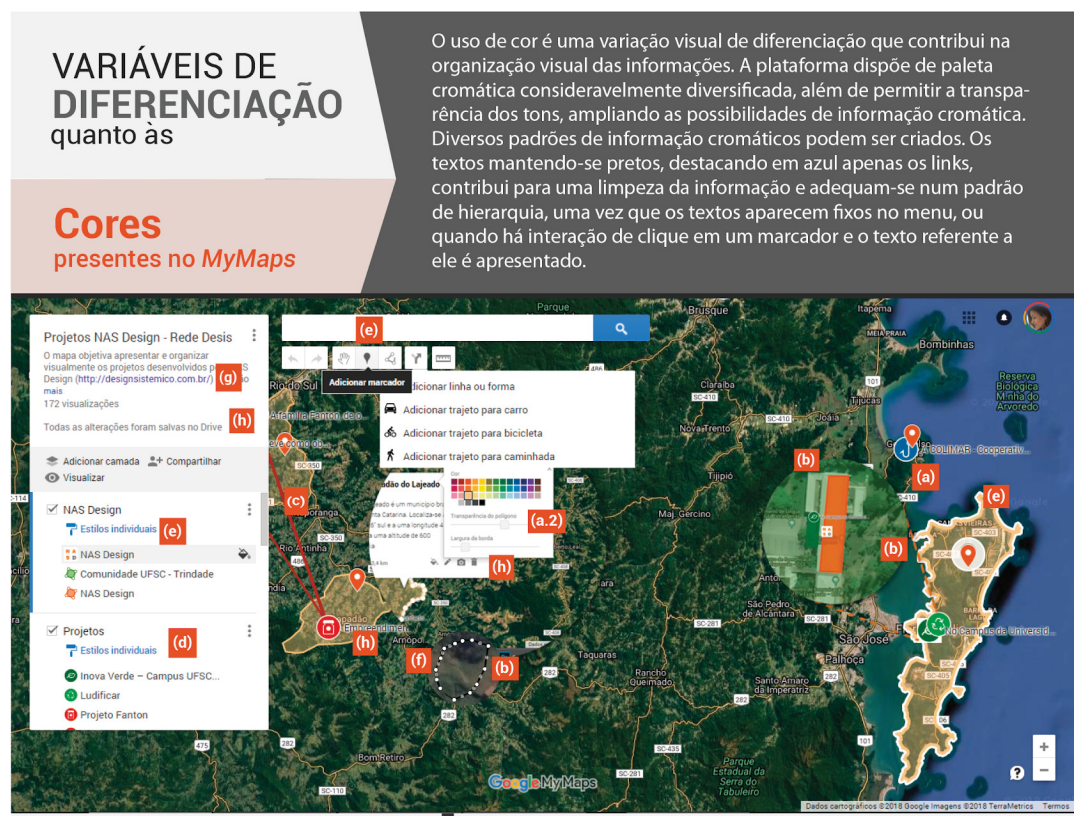

(a) marcadores Indicam cidades e pontos específicos, como os projetos. Dois tipos de marcadores foram usados, o dos projetos com cores relacionadas às suas temáticas, $\mathrm{e}$ laranja, seguindo as cores da identidade do grupo, para indicar as cidades onde o NASDe sign atua. Ícones personalizados, como os usados nos projetos, nāo podem ter as cores editadas depois de inseridos na plataforma.

(a.2) cores dos marcadores Os marcadores do sistema da plataforma possuem 44 opçōes de cores.

(d) Conteúdo das camadas As cores dos elementos usados o mapa são replicadas nos ícones do menu. Facilitando a associação dos conteúdos.

(e) Informaçāo sobre a interaçāo Nas áreas clicáveis e selecionadas dos menus das ferramentas de desenho, a plataforma adota o cinza claro para comunicar a intera çāo. Assim como quando uma forma ou linha são selecionadas, a plataforma utiliza um contorno branco.

Figura 7: Infográfico das variáveis de diferenciação quanto às cores

Fonte: Os autores. (b) formas Podem ser utilizadas para demarcar uma cidade ou uma área específica, como a sede do NAS Design. As formas podem ter as 44 cores, podendo ter variação de tonalidade a partir da escolha de transparência em 0 a $100 \%$. No mapa criado, as formas indicam as cidades e os locais específicos dos projetos, como sede de cooperativas, como a horta criada pelo núcleo como ressignificação de uma área inutilizada na UFSC. Para a indicaçāo do local específico dos projetos, aplica-se a cor referen te ao ícone do projeto.

(c) Linhas Podem ser usadas para criaçăo de linhas e formas, conectando os pontos até fechar uma forma. As linhas seguiram as cores dos projetos específicos. Foram utilizadas para conectar projetos de mesmo tema, criando uma malha direta de visualizaçāo das relaçōes entre os projetos. As linhas aparecem como contornos das formas, sendo escolhidas conforme se opta por ter largura de borda. Para os contornos, a transparência não é aplicada, se destacando em relação à forma, caso esta possua a opçāo de contorno. Os contornos ajudam a destacar divisōes entre as áreas. A cor da linha de contorno limita-se a ser a mesma cor aplicada na forma.

(f) Desenho de linhas e formas A plataforma comunica uma linha preta que vai demarcando a linha ou a forma em criaçāo e um ponto branco que indica o início do desenho desses elemen tos, bem como, a série de nós que vāo sendo exibidos para delimitar a forma e indicar o ponto de encontro entre as linhas para o fechamento da forma. A cor final pode ser editada.

(h) janelas de ediçāo e conteúdo Sảo todas na cor branca, mantendo um padrão visual em cor neutra. 


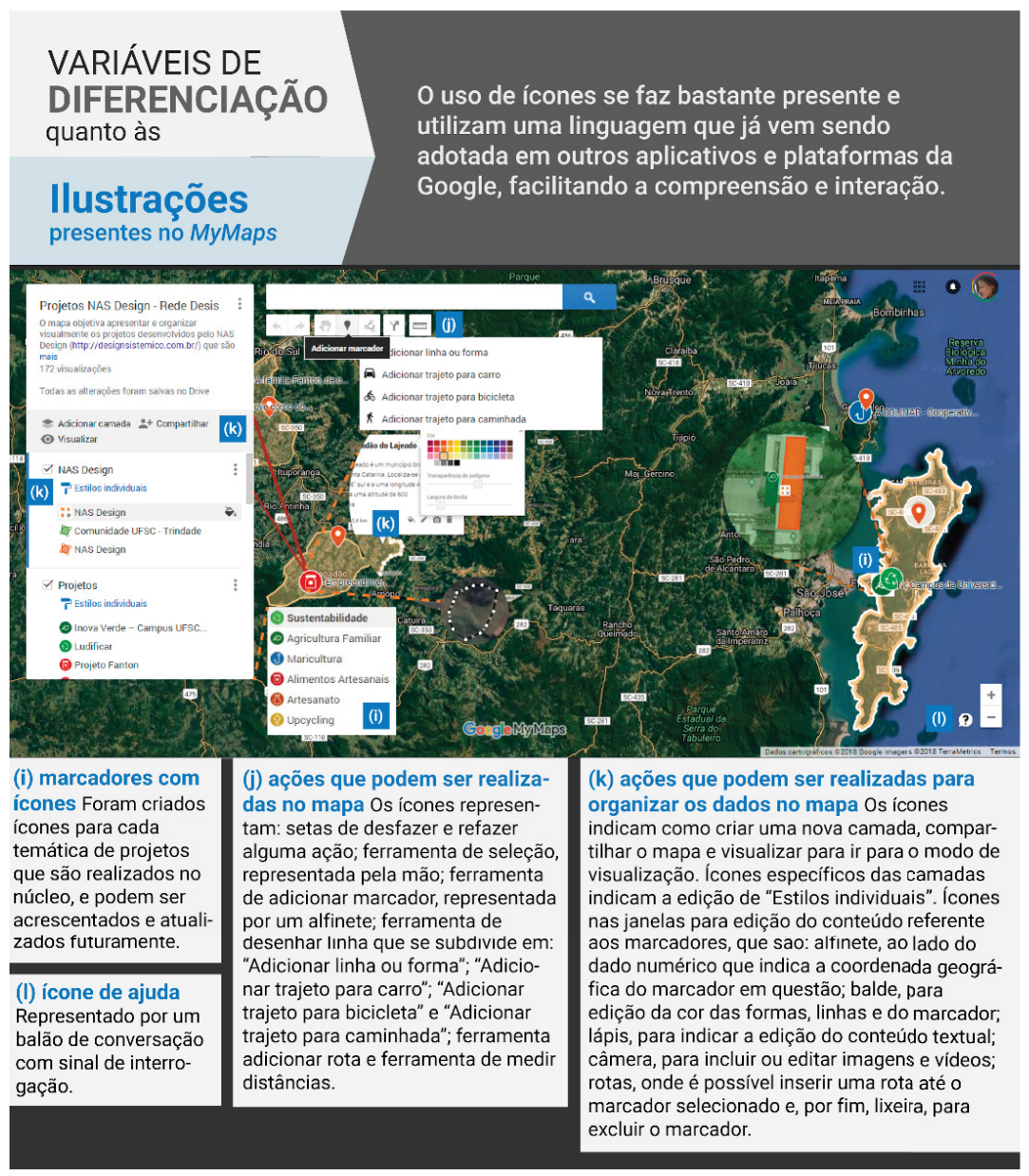

Quanto à hierarquia, os elementos disponíveis e explorados para a criação do mapa são especificados na Figura 9.

\begin{tabular}{ll} 
Hierarquia & Elementos em que as variações se dão: \\
\hline Posição sequencial cronológica & (a) indicação cronológica dos projetos \\
Posição na página (leiaute) & $\begin{array}{l}\text { (b) menu do mapa; (c) barra de busca; (d) menu de ferramentas } \\
\text { de desenho; (e) mapa; (f) botão de ajuda; (g) botões de zooming }\end{array}$ \\
Tamanho das fontes e peso & $\begin{array}{l}\text { (h) titulo do mapa; (i) texto de descrição do mapa; (j) titulo do } \\
\text { projeto; (k) descrição do projeto; (l) legenda de apoio das } \\
\text { ferramentas de desenho }\end{array}$ \\
Espaçamento das linhas & (m) textos de descrição
\end{tabular}

Figura 8: Infográfico das variáveis de diferenciação quanto às llustrações

Fonte: Os autores.
Figura 9: Lista de elementos com características de hierarquia que são possíveis de implementar e foram utilizadas na criação do mapa temático

Fonte: Os autores. 
Figura 10: Infográfico das variáveis de Hierarquia

Fonte: Os autores

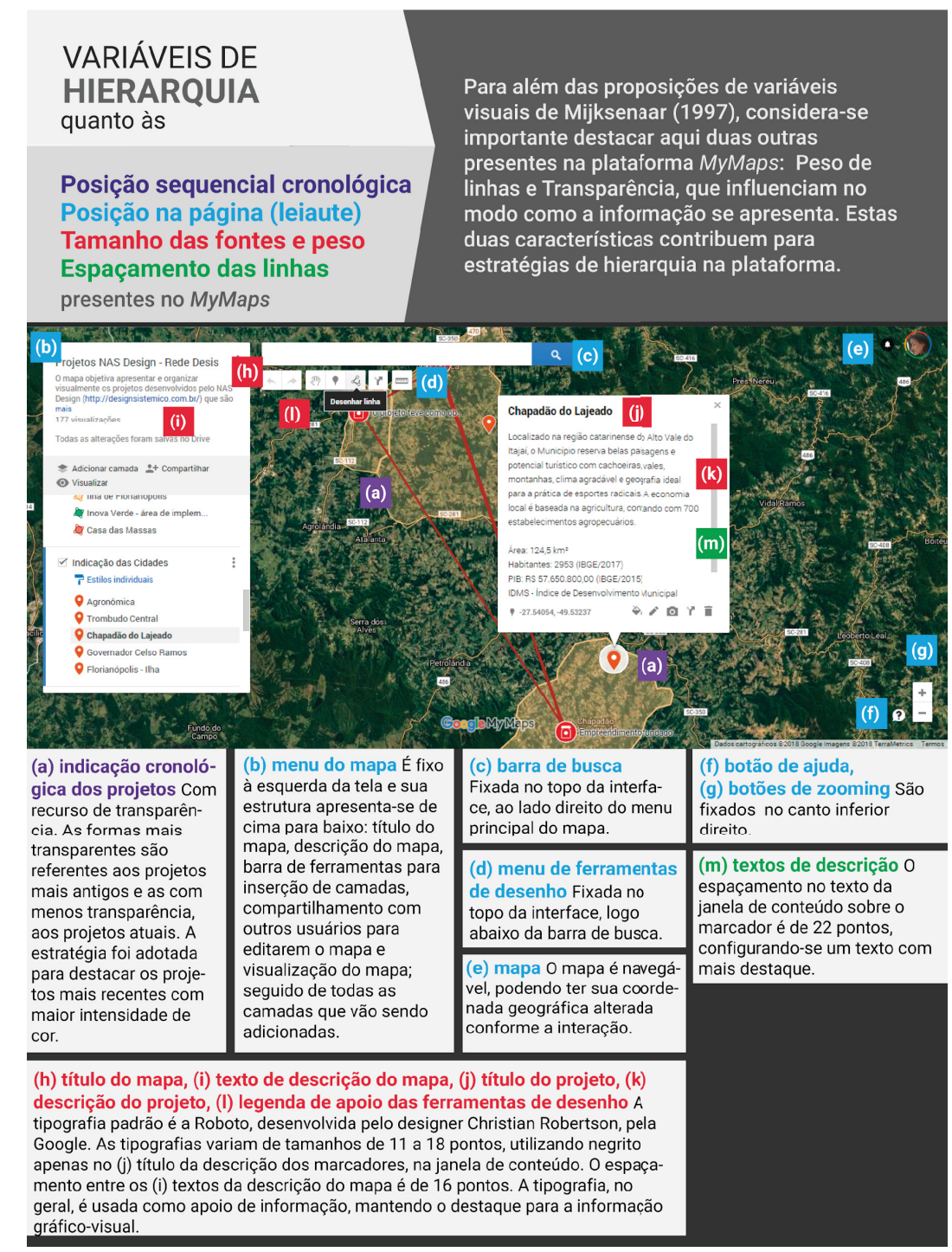

\section{VARIAVEIS DE HIERARQUIA}

(a) indicação cron gica dos projetos Com

(h) título do mapa, (i) texto de descrição do mapa, (j) título do projeto, (k) cricão do projeto, (I) legenda de apoio das ferramentas de desenho

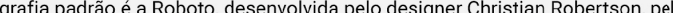
oogle. As tipografies variam de tamanhos de 11 a 18 pontos, utilizando negrito gráfico-visual.

\begin{tabular}{ll} 
Apoio & Elementos em que as variações se dão: \\
\hline Áreas de cores e sombras & (a) demonstração de relevo do mapa \\
Linhas e blocos & (b) janela de conteúdo referente ao marcador \\
Atributos do texto & (c) indicação de hiperlink \\
Imagens e vídeos & (d) janela de conteúdo
\end{tabular}

Figura 11: Lista de elementos com características de apoio que são possíveis de implementar e foram utilizadas na criação do mapa temático

Fonte: Os autores 


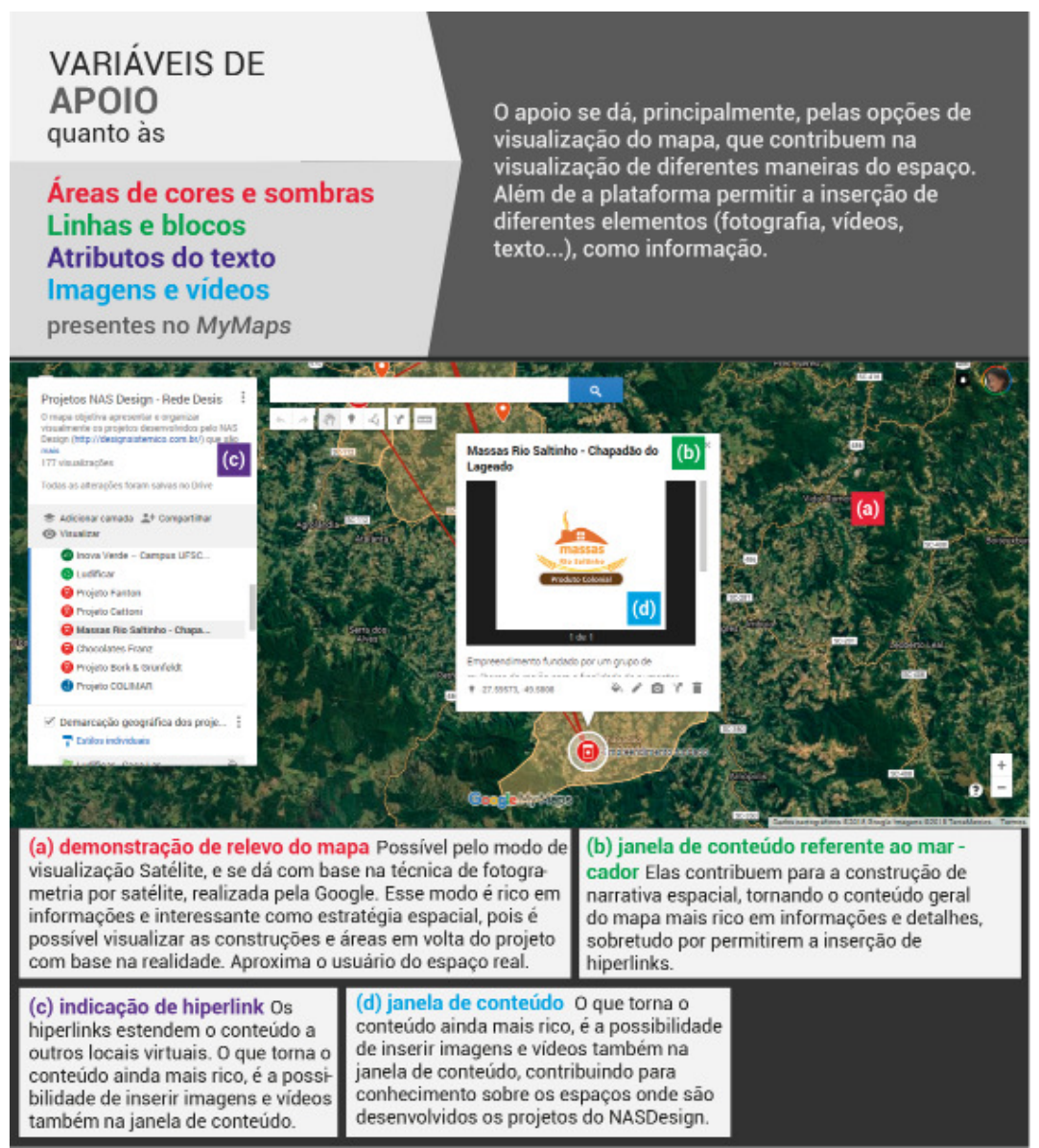

\section{DISCUSSÕES}

Após a análise dos elementos e variações visuais que são possíveis de explorar na plataforma, na sua versão gratuita e sem uso de programações para customizações, pode-se concluir que a mesma oferece variados modos de informação visual. Como no caso do mapa criado, foi possível traçar um padrão para a criação do mapa temático qualitativo, seguindo o método de mapeamento apresentado por Loch (2006) e Archela e Théry (2008).

Quanto aos critérios de mapeamento escolhidos pelos autores para a criação do mapa, o My Maps demonstrou ser eficiente. Mas, foi importante ter como base o conhecimento de métodos de mapeamento que permitiram criar uma lógica para organizar a informação de modo a torná-la acessível, contribuindo para a competência em informação de mapas, por meio de uma codificação adequada de métodos cartográficos.

No entanto, quanto a algumas funcionalidades para a criação de mapas quantitativos, seguindo o método de mapeamento, a plataforma se torna um tanto limitada. Pois, não é possível inserir pontos (ou marcadores) e editar seus tamanhos individualmente - os tamanhos são padronizados e se ajustam conforme o zooming (quanto menos zoom, maiores ficam os ícones, quanto mais zoom, menores ficam). E essa técnica é bastante utilizada em mapas quantitativos, para indicar concentração de informações em determinada região a partir da diferenciação de tamanho dos elementos. $\mathrm{Na}$ gestão dos projetos, essa condição dificulta a visualização de todos os projetos mapeados, pois os ícones aumentam e se sobrepõem, ocultando alguns marcadores próximos, comprometendo a interação com a interface. Do mesmo modo, não permite hierarquizar por tamanho de marcadores
Figura 12: Infográfico das variáveis de Apoio

Fonte: Os autores. 
os projetos (projetos guarda-chuvas, ou mais recentes por exemplo), o que facilitaria o acesso a informações mais intuitivamente e rapidamente. Assim como não é possível aplicar texturas sobre as formas desenhadas ou duplicá-las para aplicação de textura, por meio de sobreposição, como linhas ou pontos para diferenciar algumas áreas de outras. Esse recurso também é bastante utilizado na cartografia para destacar informações a fim de representar diferentes fenômenos (ARCHELA; THÉRY, 2008) e facilitaria na gestão visual dos projetos.

Outro ponto que poderia ser aprimorado seria as cidades e estados virem pré-demarcados. Por não ter essas demarcações, dificulta o desenho e destaque das formas para indicar as regiões no mapa de forma precisa, embora no desenho de mapas seja comum o uso de representações aproximadas, aceitando algumas abstrações (LOCH, 2006).

A avaliação final é de que a plataforma intenciona mais para a concentração de informações, demarcando espacialmente e descrevendo, do que necessariamente para a criação de mapa analítico ou de síntese (ARCHELA; THÉRY, 2008). Esta percepção é sustentada, ainda, pelo fato de não ser possível criar uma legenda específica para os elementos ou formas que compõem o mapa, o que dificulta a gestão de projetos, tendo que utilizar recursos alternativos como inserção de informações em camadas ou nas janelas de texto dos projetos.

\section{CONSIDERAÇÕES FINAIS}

A partir do estudo realizado, compreendeu-se o My Maps como um ambiente digital com propriedades mais espaciais e enciclopédicas, segundo as definições de Murray (2003). A plataforma oferece mais autonomia na inserção de conteúdo do que necessariamente na aplicação de informação gráfica visual com diferenciações. Tal característica tem sua riqueza, e pode ser explorada para a construção de sentido, trazendo dados específicos de regiões, da população e dos atores que nelas vivem. Entende-se que favorece a inserção de conteúdo sobre determinada região, local ou estabelecimento para que um usuário os receba, conhecendo mais sobre o local apontado ou destacado no mapa. Mas, também apresenta um aspecto procedimental, uma vez que possibilita a criação de regras para criação do mapa, podendo criar previamente critérios, seguindo alguns métodos, e depois transpor para a plataforma, criando um padrão de comunicação e interação, o que facilita o uso na gestão de projetos.

O mapa desenvolvido neste estudo, envolve projetos de design relacionados à sustentabilidade, em um processo holístico, composto por múltiplas variáveis como: diferentes atores, análise de recursos disponíveis e de possíveis novas interações com foco no sistema produtivo local. O mapa criado permite localizar por categorias os projetos, o que facilita pensar estratégias de articulações entre os atores locais, conectando projetos, recursos e atores para diversas soluções. A interação, neste caso, ficou limitada aos pesquisadores do núcleo, os quais alimentam a plataforma com novos projetos. O mesmo foi implementado em junho de 2018. A plataforma permite uma visualização ampla e contextualizada geograficamente sobre os pontos de ação de projetos, além de contribuir para a divulgação dos mesmos e das comunidades parceiras utilizando o mapa como plataforma comunicativa. Assim, o uso de MDI contribui para: localizar atores de um sistema e rotas possíveis; analisar o ambiente ao entorno de organizações; concentrar informações, gerar insights conectivos entre outras possibilidades que auxiliam na análise de dados, podendo sustentar a gestão de design em nível estratégico (MOZOTA, 2011), bem como difundir projetos realizados.

Para a criação do mapa, o conhecimento sobre os métodos de mapeamento se mostrou fundamental para organizar a lógica da apresentação dos dados, criando uma visualização da informação melhor estruturada, importante para o auxílio da gestão de projetos. Do mesmo modo, os conhecimentos de design da informação foram fundamentais para orientar essa organização. 
Percebeu-se que os métodos de mapeamento ainda não avançaram para contemplar as possibilidades dos mapas digitais interativos, sendo um campo rico para pesquisas e desenvolvimento, bem como a oportunidade de explorar outras variáveis visuais para este contexto. Mas, notou-se também, as possibilidades narrativas nessa plataforma que contribuem para a valorização de histórias locais.

\section{AGRADECIMENTO}

Agradecemos à CAPES pela concessão de bolsas que viabilizaram as pesquisas e todos os projetos que foram mapeados.

\section{REFERÊNCIAS BIBLIOGRÁFICAS}

ARCHELA, R. S.; THÉRY, H. Orientação metodológica para construção e leitura de mapas temáticos. In: Confins [Online], v. 3, 2008. DOI: 10.4000/confins.3483. Acesso em: 03 maio 2018.

BERTIN, J. A neográfica e o tratamento gráfico da informação. Curitiba: UFPR, 1986. $273 p$.

BRESSANE, T. Navegação e construção de sentido. In: FERRARI, Pollyana. Hipertexto, hipermídia: as novas ferramentas de comunicação digital. 1. Ed. São Paulo : Contexto, 2010. p. 149-163.

CARDOSO, R. Design para um mundo complexo. São Paulo: Cosac Naify, 2013.

DESIS. Disponível em: <http://desis-network.org/> Acesso em: 20 out. 2017.

DICK, M. E.; GONÇALVES, B. S.; VITORINO, E. V. Design da informação e competência em informação: relações possíveis. In: Infodesign. v. 17. n. 1. 2017. p. 1-13. Disponível em: https://www.infodesign.org.br/infodesign/article/view/500. Acesso em: 15 out. 2018.

FALAT, D. R. Avaliação de mapas na web: questões relativas à interface e à interatividade. [Dissertação]. Florianópolis: Universidade Federal de Santa Catarina, Pós-Graduação em Ciências Geodésicas. Departamento de Geomática, 2007. $134 \mathrm{p}$

FREIRE, P. de S. Aumente a qualidade e quantidade de suas publicações científica: manual para elaboração de projetos e artigos científicos. Curitiba: CRV, 2013.

FREITAS, J. C. O design como interface de comunicação e uso em linguagem hipermidiática. In: LEÃO, L. 0 chip e o caleidoscópio. Reflexões sobre as novas mídias; São Paulo: SENAC, 2005. P. 183-196.
JOLY, M. P.; STRAIOTO, R. E FIGUEIREDO, L. F. Strategies in design for social innovation within Alto Vale Project. Strategic Research Design Journal. Porto Alegre: UNISINOS, 2015. DOI: 10.4013/ sdrj.2014.72.04 Acesso em: 10 jan. 2019.

$\mathrm{LOCH}$, R. E. N. Cartografia: representação, comunicação e visualização de dados espaciais. Florianópolis: Editora UFSC, 2006. $313 \mathrm{p}$

MANOVICH, L. Novas mídias como tecnologia e ideias: dez definições. In: LEÃO, Lucia. 0 chip e o caleidoscópio: reflexões sobre as novas mídias. São Paulo: Senac, 2005. p. 24-50.

MANZINI, Ezio. Design: Quando Todos Fazem Design. São Leopoldo: Editora: Unisinos, 2017.

MARTORANO, Mariana. Sistematização das atividades do NAS Design com foco na abordagem sistêmica para gestão de design. Dissertação (Mestrado em Design e Expressão Gráfica) Universidade Federal de Santa Catarina, Florianópolis, Santa Catarina, 2012.

MARTINO, L. M. S. Teoria das Mídias Digitais: linguagens, ambientes, redes. Petrópolis: Vozes, 2014.

MIJKSENAAR, Paul. Visual function: an introduction to information design. Rotterdam: 010 Publichers, 1997.

MOZOTA, B. B.de. Gestão do Design: usando o design para construir valor na marca e inovação corporativa. Porto Alegre: Bookman, 2011.

MURRAY, J. H. Hamlet no holodeck: o futuro da narrativa no ciberespaço. São Paulo: Itaú Cultural: Unesp, 2003.

OLIVEIRA, T. K. de. Descontruindo mapas, revelando espacializações: reflexões sobre o uso da cartogra- 
fia em estudos sobre o Brasil colonial.

Revista Brasileira de História, São

Paulo, v. 34, n. 68, p.151-174, jul. 2014. DOl: $\quad$ https://doi.org/10.1590/s010201882014000200008. Acesso em: 25 abr. 2018.

PRATES, R. O. Interação em sistemas colaborativos. In: PIMENTEL, M, FUCKS, H. Sistemas Colaborativos. RJ: Elsevier, 2011. p. 264-293.

QUINTÃO, F. Design de informação em plataformas colaborativas online baseadas na imagem cartográfica digital. Dissertação (Mestrado em Design e Expressão Gráfica, Departamento de Design, 2013. 200 p.

QUINTÃO, F.; TRISKA, R. Design de informação em interfaces digitais: origens, definições e fundamentos. In: Infodesign. v. 10. n. 2. p. 105-118. São Paulo, 2013. Disponível em: < https://www.infodesign. org.br/infodesign/article/view/243> Acesso em: 21 abr. 2018.

REIS, L. E. dos. Garimpo v: desenvolvimento de interfaces gráficas para um aplicativo com informações geolocalizadas para o público vegano. 2017. 117 f. TCC (Graduação) - Curso de Design, Universidade Federal de Santa Catarina, Florianópolis, 2017. Disponíve em: $\quad<$ https://repositorio.ufsc.br/handle/123456789/177177>. Acesso em: 20 abr. 2018.

SOUSA, P. Criação de uma plataforma websig de equipamentos culturais e desportivos para a região autónoma dos açores: caso de estudo para a ilha de São Miguel. Relatório de Estágio (Mestrado em Ciência e Sistemas de Informação Geográfica). NOVA IMS, Lisboa, 2015. Disponível em: <https:// run.unl.pt/bitstream/10362/18430/1/ TSIG0115.pdf>. Acesso em: 20 abr. 2018.

\section{Karina Pereira Weber} karinaweber.rs@gmail.com

Larissa Fontoura Berlato lari.berlato@gmail.com

Berenice Santos Gonçalves berenice@cce.ufsc.br

Luiz Fernando G. de Figueiredo luiz.fernando@ufsc.br 